\title{
Long-term results of a phase II study with neoadjuvant docetaxel chemotherapy and complete androgen blockade in locally advanced and high-risk prostate cancer
}

Mark Thalgott ${ }^{1 *}$, Thomas Horn ${ }^{1}$, Matthias M Heck' ${ }^{1}$, Tobias Maurer ${ }^{1}$, Matthias Eiber², Margitta Retz', Michael Autenrieth ${ }^{1}$, Kathleen Herkommer ${ }^{1}$, Bernd J Krause ${ }^{3}$, Jürgen E Gschwend ${ }^{1}$, Uwe Treiber ${ }^{1}$ and Hubert R Kübler ${ }^{1}$

\begin{abstract}
Background: Patients with locally advanced and high-risk prostate cancer (LAPC) are prone to experience biochemical recurrence despite radical prostatectomy (RP). We evaluated feasibility, safety and activity of a neoadjuvant chemohormonal therapy (NCHT) with 3-weekly full dose docetaxel and complete androgen blockade (CAB) in locally advanced and high-risk prostate cancer patients (LAPC) undergoing RP.

Methods: Patients $(n=30)$ were selected by Kattans' preoperative score and received trimestral buserelin $9,45 \mathrm{mg}$, bicalutamide $50 \mathrm{mg} /$ day and 3 cycles docetaxel $\left(75 \mathrm{mg} / \mathrm{m}^{2}\right)$ followed by RP. Primary endpoints were biochemical (PSA) and local downstaging. Secondary endpoints included toxicity and operability assessments, pathological complete response (pCR), time to PSA progression, 5-year biochemical recurrence free survival (bRFS) and overall survival (OS).
\end{abstract}

Results: Median baseline PSA was $25.8 \mathrm{ng} / \mathrm{ml}$ (2.1-293), and the predicted probability of 5-year bRFS was 10\% (0-55). NCHT induced PSA-reduction was 97.3\% (81.3-99.9\%; $p<0.001$ ) and post-RP 96.7\% of patients were therapy responders, with undetectable PSA-values. Post- vs. pretreatment MRI indicated a median tumor volume reduction of $46.4 \%(-31.3-82.8 ; p<0.001)$. A pathological downstaging was observed in $48.3 \%$. Severe hematologic toxicities ( $\geq$ CTC3) were frequent with $53.8 \%$ leucopenia, $90 \%$ neutropenia and $13.3 \%$ febrile neutropenia. RP was performed in all patients. While resectability was hindered in $26.7 \%$, continence was achieved in $96.7 \%$. Pathologic analyses revealed no pCR. Lymph node- and extracapsular involvement was observed in $36.7 \%$ and $56.7 \%$ with $33.3 \%$ positive surgical margins. After a median of 48.6 (19.9-87.8) months, 55.2\% of therapy responders experienced PSA-recurrence. The estimated median time to PSA-progression was 38.6 months ( $95 \% \mathrm{Cl} 30.9-46.4)$ and 85.3 months (95\% Cl 39.3-131.3) for OS. The 5-year bRFS was improved to 40\%, but limiting for interpretation adjuvant treatment was individualized.

Conclusions: NCHT is feasible despite high hematotoxicity, with excellent functional results. Significant downstaging was observed without PCR. NCHT seems to improve the cohort adjusted 5-year bRFS, but clinical value needs further investigation in randomized trials.

Keywords: Chemohormonal therapy, Complete androgen blockade, Docetaxel, Prostate cancer, Neoadjuvant treatment

\footnotetext{
* Correspondence: mark.thalgott@|rz.tum.de

'Department of Urology, Klinikum rechts der Isar, Technische Universität

München, Ismaninger Str. 22, Munich 81675, Germany

Full list of author information is available at the end of the article
} 


\section{Background}

Patients with locally advanced and high-risk prostate cancer (LAPC) are prone to experience biochemical recurrence despite curative-intended radical prostatectomy (RP). Predictor variables are PSA-value, clinical stage and Gleason score [1,2]. In order to improve clinical outcome, neoadjuvant regimens combined with curative treatment options are investigated [3]. In contrast to approved androgen deprivation therapies (ADT) concomitant to external beam radiation, there is no standardized systemic perioperative regimen for LAPC patients undergoing RP [3-5]. Presurgical ADT induces downstaging with reduced positive surgical margins and lymph node metastases but fails to improve survival or to induce relevant pathological complete response $(\mathrm{pCR})$ rates $[6,7]$.

In castration-resistant prostate cancer patients (CRPC), docetaxel chemotherapy (D) is standard of care due to prolonged survival in randomized phase III trials [8-11]. Subsequently, docetaxel was investigated for neoadjuvant treatment in patients with locally advanced PC. Similar to neoadjuvant $\mathrm{ADT}$, preoperative docetaxel monotherapy did not improve survival and no pCR was observed, despite PSA-reduction and local downstaging [3,12-14].

Since androgen-dependent and -independent cell subpopulations may coexist, neoadjuvant strategies combining docetaxel and complete androgen blockade (CAB) were investigated, still resulting in deficient pCR rates of 3-6\% $[15,16]$. In favor of reduced morbidity, the latter trials used weekly regimens of docetaxel, albeit 3-weekly administered docetaxel demonstrated superior clinical efficacy in comparison to weekly schedules, in CRPC patients $[8,9]$.

The combination of $\mathrm{CAB}$ with a 3-weekly full dose regimen of docetaxel $\left(75 \mathrm{mg} / \mathrm{m}^{2}\right)$, over a period of 3 cycles (9 weeks), may exhibit superior activity to downstage tumors and improve oncological outcome. Therefore, we prospectively determined feasibility, safety and activity of this presurgical short-term combination therapy in 30 LAPC patients undergoing RP.

\section{Results}

\section{Patient characteristics}

The clinical patient characteristics are outlined in Table 1. Between July 2005 and February 2010, 30 patients were enrolled. Median pretreatment values were $25.8 \mathrm{ng} / \mathrm{ml}$ for PSA, 7 for biopsy Gleason score, cT3b for clinical stage and 68 years for age. According to Kattan's nomogram, the median probability of bRFS was $10 \%$ (range $0-55$ ) [1].

\section{Neoadjuvant treatment and toxicity profile}

Overall 86 cycles of docetaxel were administered and 27 (90\%) patients completed all 3 cycles. Three patients (10\%) discontinued NCHT; one withdrew consent after one cycle, and two interrupted due to NCHT-unrelated severe $\mathrm{AE}$ (lumbar disk herniation; exacerbating peripheral
Table 1 Pretreatment clinical characteristics

\begin{tabular}{|c|c|}
\hline Clinical characteristics & Value \\
\hline Patients (n) & 30 \\
\hline \multicolumn{2}{|l|}{ Age (yr.) } \\
\hline Median (mean) & $68(65.9)$ \\
\hline Range & $52-76$ \\
\hline ECOG & $30(100 \%)$ \\
\hline \multicolumn{2}{|l|}{0} \\
\hline \multicolumn{2}{|c|}{ Prostate specific antigen (ng/ml) } \\
\hline Median (mean) & $25.8(43.2)$ \\
\hline Range & $2.1-293.0$ \\
\hline \multicolumn{2}{|l|}{ Gleason score at diagnosis } \\
\hline 6 & $3(10.0 \%)$ \\
\hline 7 & $14(46.7 \%)$ \\
\hline 8 & $6(20.0 \%)$ \\
\hline 9 & 7 (23.3\%) \\
\hline \multicolumn{2}{|l|}{ Clinical stage } \\
\hline $\mathrm{T} 2 \mathrm{C}$ & $2(6.7 \%)$ \\
\hline Т3а & $6(20.0 \%)$ \\
\hline T3b & $21(70.0 \%)$ \\
\hline $\mathrm{T} 4$ & $1(4.3 \%)$ \\
\hline \multicolumn{2}{|l|}{ Kattan score } \\
\hline Median (mean) & $172(171)$ \\
\hline Range & $125-200$ \\
\hline \multicolumn{2}{|c|}{ Probability of 5-year bRFS (\%) } \\
\hline Median (mean) & $10(10)$ \\
\hline Range & $0-55$ \\
\hline
\end{tabular}

arterial occlusion disease (PAOD)) after two cycles of docetaxel. Bicalutamide was continued up to RP except for the patient with PAOD. Dose reductions of docetaxel were necessary in two patients (6.7\%) and a treatment deferral in one patient (3.3\%). Adverse events occurring in $\geq 10 \%$ of patients are presented in Table 2. Grade 3/4 nonhematologic toxicities were pneumonia (3.3\%) and hyperglycemia (3.3\%). Grade 3/4 hematologic toxicities were leucopenia in $53.8 \%(\mathrm{n}=14)$ and neutropenia in $90 \%$ $(\mathrm{n}=18)$, in patients amenable for hematologic analyses one week after docetaxel administration. Febrile neutropenia was observed in $13.3 \%$. Late toxicity assessments after a median follow up (FU) of 48.6 months (range 14.1-87.8) revealed one case $(3.3 \%)$ of lower neuropathy (Grade 1). Second malignancies were observed in 2 cases (6.7\%), one patient with bronchial carcinoma and another patient with bladder cancer, who received adjuvant radiation therapy.

\section{Surgical and pathological outcome}

All patients $(\mathrm{n}=30)$ underwent RP with histopathological analyses after a median interval of 70 days from 
Table 2 Adverse events, according to CTC grades, occurring in $>10 \%$ of patients

\begin{tabular}{|c|c|c|c|c|c|}
\hline Toxicity & $\begin{array}{l}\text { Patients } \\
\text { n }\end{array}$ & $\begin{array}{l}\text { Grade } 1 \\
\text { n (\%) }\end{array}$ & $\begin{array}{l}\text { Grade } 2 \\
\text { n (\%) }\end{array}$ & $\begin{array}{l}\text { Grade } 3 \\
\text { n (\%) }\end{array}$ & $\begin{array}{l}\text { Grade } 4 \\
\mathrm{n}(\%)\end{array}$ \\
\hline Alopecia & 30 & $18(60.0)$ & $11(36.7)$ & 0 & 0 \\
\hline Fatigue and asthenia & 30 & $14(46.7)$ & $14(46.7)$ & 0 & 0 \\
\hline Sensory neuropathy & 30 & $9(30.0)$ & $4(13.3)$ & 0 & 0 \\
\hline Edema & 30 & $16(53.3)$ & 0 & 0 & 0 \\
\hline Nausea and vomiting & 30 & $10(30.0)$ & 0 & 0 & 0 \\
\hline Diarrhea & 30 & $6(20.0)$ & $1(3.3)$ & 0 & 0 \\
\hline Constipation & 30 & $4(13.3)$ & 0 & 0 & 0 \\
\hline Stomatitis & 30 & $10(33.3)$ & $3(10.0)$ & 0 & 0 \\
\hline Febrile neutropenia & 30 & 0 & 0 & $3(10.0)$ & $1(3.3)$ \\
\hline Skin rash & 30 & $6(20.0)$ & 0 & 0 & 0 \\
\hline Arthralgia and myalgia & 30 & $4(13.3)$ & $1(3.3)$ & 0 & 0 \\
\hline Perspiration & 30 & $8(26.7)$ & $1(3.3)$ & 0 & 0 \\
\hline Dysgeusia & 30 & $15(50.0)$ & $5(16.7)$ & 0 & 0 \\
\hline Nail changes & 30 & $18(60.0)$ & 0 & 0 & 0 \\
\hline Hot flush & 30 & $12(40.0)$ & $2(6.7)$ & 0 & 0 \\
\hline Depressive symptoms & 30 & $8(26.7)$ & $1(3.3)$ & 0 & 0 \\
\hline Insomnia & 30 & $8(26.7)$ & 0 & 0 & 0 \\
\hline Dyspepsia and abdominal pain & 30 & $6(20.0)$ & 0 & 0 & 0 \\
\hline Sore throat and dysphagia & 30 & $5(16.7)$ & $2(6.7)$ & 0 & 0 \\
\hline Chill & 30 & $4(13.3)$ & 0 & 0 & 0 \\
\hline Increased urea & 28 & $18(64.3)$ & 0 & 0 & 0 \\
\hline Increased potassium & 30 & $4(13.3)$ & 0 & 0 & 0 \\
\hline Hypoproteinemia & 23 & $4(17.4)$ & 0 & 0 & 0 \\
\hline Increased GGT & 27 & $4(14.8)$ & $1(3.7)$ & 0 & 0 \\
\hline Increased GPT & 27 & $4(14.8)$ & 0 & 0 & 0 \\
\hline Increased LDH & 22 & $20(90.9)$ & 0 & 0 & 0 \\
\hline Anemia, day 21 & $25^{\#}$ & $12(48.0)$ & 0 & 0 & 0 \\
\hline Anemia, day 7 & $21^{\#}$ & $16(76.2)$ & 0 & 0 & 0 \\
\hline Leucopenia, day 7 & 26 & $5(19.2)$ & $4(15.4)$ & $10(38.5)$ & $4(15.4)$ \\
\hline Neutropenia, day 7 & 20 & 0 & $1(5.0)$ & $4(20.0)$ & $14(70.0)$ \\
\hline
\end{tabular}

Abbreviations: CTC, Common Terminology Criteria for Adverse Events; GGT, Gamma-Glutamyl-Transferase; GPT, Glutamat-Pyruvat-Transaminase; LDH, Lactate Dehydrogenase; \#, five patients excluded due to preexisting anemia at inclusion.

day 1 (range 61-143). Median removed lymph nodes were 16 (range 5-39). Surgical variables are depicted in Table 3 and pathological results in Table 4. Resectability was hindered due to periprostatic fibrosis in $23.3 \%$ and to increased vulnerability with increased diffuse bleeding in $3.3 \%$. In case of periprostatic fibrosis the identification and dissection of the appropriate surgical layers was more difficult, when compared to not pretreated patients. Early re-interventions were required due to symptomatic lymphoceles $(20 \%)$, hydronephrosis $(3.3 \%)$ and bleeding (3.3\%). Late events were urethral strictures (6.7\%). Pathological analyses revealed extracapsular extension in $56.5 \%$ with positive surgical margins (R1) in
$33.3 \%(\mathrm{n}=10)$ and lymph node involvement $(\mathrm{pN} 1)$ in $36.7 \%$ of patients $(\mathrm{n}=11)$.

Long time functional outcome, following a median of 48.6 months (range 14.1-87.8), revealed continence in 96.7\%. Before treatment $86.7 \%(\mathrm{n}=26)$ patients were potent. After RP 15.4\% had spontaneous erections (E3-E4), $11.5 \%$ were potent with erection aids and $19.2 \%$ had tumescence sufficient for sexual activity but not for vaginal penetration (E1-E2).

\section{Clinical activity}

All patients $(\mathrm{n}=30)$ demonstrated a PSA reduction following $\mathrm{NCHT}$ with a median decline of $97.3 \%$ (range 
Table 3 Surgical variables and complications

\begin{tabular}{|c|c|}
\hline Variable & Value \\
\hline Patients with radical prostatectomy, $\mathrm{n}$ & 30 \\
\hline \multicolumn{2}{|l|}{ Surgery hindered, n (\%) } \\
\hline Fibrosis & $7(23.3)$ \\
\hline Vulnerability & $1(3.3)$ \\
\hline \multicolumn{2}{|l|}{ Surgery duration, min ${ }^{\#}$} \\
\hline Median (mean) & $195(208.7)$ \\
\hline Range & $140-333$ \\
\hline \multicolumn{2}{|l|}{ Nerve sparing, n (\%) } \\
\hline Bilateral & $6(20.0)$ \\
\hline Unilateral & $3(10.0)$ \\
\hline Not possible & $21(70.0)$ \\
\hline \multicolumn{2}{|l|}{ Intraoperative blood loss, ml } \\
\hline Median (mean) & $600(769.2)$ \\
\hline Range & $100-2600$ \\
\hline \multicolumn{2}{|l|}{ No. of transfused blood units, n } \\
\hline Median (mean) & $0(0.9)$ \\
\hline Range & $0-5$ \\
\hline \multicolumn{2}{|l|}{ Complications, needing intervention, $\mathrm{n}(\%)^{\S}$} \\
\hline Symptomatic pelvic hematoma & $1(3.3)$ \\
\hline Hydronephrosis & $1(3.3)$ \\
\hline Lymphocele & $6(20.0)$ \\
\hline \multicolumn{2}{|l|}{ Complications in $\geq 10 \%$ of cases, $n(\%)^{\S}$} \\
\hline Joint pain & $3(10.0)$ \\
\hline Venous/pulmonary thromboembolism & $5(16.7)$ \\
\hline \multicolumn{2}{|l|}{ Time to catheter removal, days } \\
\hline Median (mean) & $8(13.1)$ \\
\hline Range & $7-47$ \\
\hline \multicolumn{2}{|l|}{ Continence, no. of pads, n (\%)* } \\
\hline 0 & $29(96.7)$ \\
\hline$\geq 1$ & $1(3.3)$ \\
\hline \multicolumn{2}{|l|}{ Erectile function $(n=26), n(\%)^{*}$} \\
\hline Potent (E 3-4) & $4(15.4)$ \\
\hline Potent with erection aids (E 3-4) & $3(11.5)$ \\
\hline Tumescence (E 1-2) & $5(19.2)$ \\
\hline Impotence (E 0) & $14(53.9)$ \\
\hline
\end{tabular}

Abbreviations: " skin incision to skin suture; ${ }^{5}$ within 4 weeks from surgery; *after a median follow up of 48.6 months (range 14.1-87.8).

81.3-99.9\%; $\mathrm{p}<0.001$ ) (Figure 1). Partial PSA response was observed in $100 \%$ and a complete response in $13.3 \%$. After RP $96.7 \%$ of patients were therapy responders with undetectable PSA-values.

Downstaging of the clinical T-stage, indicated by MRI, was observed in $32 \%$ of 25 evaluable patients (cT3a to cT2 $\mathrm{n}=3$; cT3b to cT2 $\mathrm{n}=2$; cT3b to cT3a $n=2$; cT4 to cT3a $\mathrm{n}=1$ ), without upstaging. Prostate volume was reduced in all cases with a significant median decrease of $37.1 \%$ (range 17.2-68.5\%; $\mathrm{p}<0.001$ ). Similarly a significant median tumor volume reduction of $46.4 \%$ (range -31.3 82.8\%; $\mathrm{p}<0.001)$ was observed in $95.7 \%(\mathrm{n}=22)$ of patients harboring measurable tumors, while one progressed (4.3\%). Pathological downstaging, comparing initial T-stages on MRI ( $n=29$ ) with histopathological stages revealed downstaging in $48.3 \%$ (cT3a to pT2 n =2; cT3b to pT2 n =10; cT3b to pT3a $n=1$; cT4 to pT3b $n=1$ ) and upstaging in $13.8 \%$ (cT2 to pT3b $n=1$; cT3a to pT3b $n=3$ ). Histopathological analyses revealed no pathological complete response (pCR), and only one (3.3\%) pathological minimal residual disease (pMRD) with a tumor volume of $<5 \%$.

\section{Time to PSA progression and overall survival}

After a median FU of 48.6 months (range 19.9-87.8), of the 29 treatment responders $55.2 \%$ experienced a biochemical progression. The estimated median time to PSA progression was 38.6 months (95\% CI 30.9-46.4) with a 5-year biochemical recurrence free survival of $40 \%$ (Figure $2 \mathrm{a}$ ).

Adjuvant ADT was administered in 7 (23.3\%) patients over a mean of 19 months (range 11-28) due to pathological R1N1 ( $=2)$ or R0N1 $(n=5)$ stages. Adjuvant radiation therapy (RT) was performed in $3(10 \%)$ patients due to positive surgical margins without lymph node involvement (R1N0). No adjuvant RT was performed in 3 patients despite a R1N0 stage in favor a deferred RT in case of biochemical recurrence and in 4 patients with a R1N1 stage.

At the time of this analysis $26(86.7 \%)$ patients were still alive. Two patients $(6.7 \%)$ experienced a PC related death. The estimated median OS in the complete cohort was 85.3 months (95\%CI 39.3-131.3) (Figure 2b).

\section{Discussion}

We investigated a short-term neoadjuvant therapy with 3weekly full dose docetaxel (D), combined with CAB in LAPC patients undergoing RP. Although presurgical docetaxel-based regimens were investigated earlier, FU data are mostly short-term (Table 4). In addition, investigating $\mathrm{D}+\mathrm{CAB}$, weekly docetaxel schedules were used, potentially exhibiting inferior clinical activity $[8,9,15,16]$. Further, a high prognostic variability was observed within and across cohorts due to study accrual following D'Amico's criteria $[2,3,15,17]$. To our knowledge we are the first to present a $\mathrm{D} \pm \mathrm{ADT}$ treated cohort recruited according to Kattan's nomogram, that allows for selection of equable high-risk populations $[1,3,17]$. Thus our cohort displays a probability of 5 -year bRFS of only $10 \%$.

With respect to non-hematologic toxicities, we observed the known profile of AE during palliative or neoadjuvant $\mathrm{D} \pm \mathrm{ADT}$. The incidence of severe $\mathrm{AE}$ was low (7\%) when compared to weekly D monotherapy (21$53 \%)$ or weekly D + CAB (21-26\%) $[12,13,15,16]$. In contrast severe hematologic toxicities were frequent with 
Table 4 Pathological and oncological results in trials using presurgical docetaxel \pm hormonal therapy

\begin{tabular}{|c|c|c|c|c|c|c|c|c|c|c|c|}
\hline \multirow{2}{*}{$\begin{array}{l}\text { Therapy } \\
\text { Author year }\end{array}$} & \multicolumn{8}{|c|}{ Docetaxel + Hormonal Therapy } & \multicolumn{3}{|c|}{ Docetaxel - Single Treatment } \\
\hline & $\begin{array}{l}\text { Current } \\
\text { series }\end{array}$ & Narita 2012 & Kim 2011 & Mellado 2009 & Sella 2008 & Chi 2008 & $\begin{array}{l}\text { Prayer-Galetti } \\
2007\end{array}$ & $\begin{array}{l}\text { Hussain } \\
2003\end{array}$ & $\begin{array}{l}\text { Magi-Galuzzi } \\
2007\end{array}$ & $\begin{array}{l}\text { Febbo } \\
2005\end{array}$ & $\begin{array}{l}\text { Dreicer } \\
2004\end{array}$ \\
\hline Patients (n) & 30 & 18 & $24^{\mathrm{RP} / \mathrm{Rad}}$ & 57 & 22 & 72 & 22 & 21 & 29 & 19 & 29 \\
\hline $\begin{array}{l}\text { Docetaxel } \\
\text { (D) Regime }\end{array}$ & $\begin{array}{l}3 \text { cycles, q21, } \\
\left(75 \mathrm{mg} / \mathrm{m}^{2}\right)\end{array}$ & $\begin{array}{l}6 \text { weeks, q7, } \\
\left(30 \mathrm{mg} / \mathrm{m}^{2}\right)\end{array}$ & $\begin{array}{l}3 \text { cycles, q7 } \\
\text { (3xD }+1 \text { week rest }) \\
\left(36 \mathrm{mg} / \mathrm{m}^{2}\right)\end{array}$ & $\begin{array}{l}3 \text { cycles, q7 } \\
(3 \times D+1 \\
\text { week rest) } \\
\left(36 \mathrm{mg} / \mathrm{m}^{2}\right)\end{array}$ & $\begin{array}{l}4 \text { cycles, q21 } \\
\left(70 \mathrm{mg} / \mathrm{m}^{2}\right)\end{array}$ & $\begin{array}{l}3 \text { cycles, q7 } \\
(6 \times D+2 \\
\text { weeks rest }) \\
\left(35 \mathrm{mg} / \mathrm{m}^{2}\right)\end{array}$ & $\begin{array}{l}4 \text { cycles, q21, } \\
\left(70 \mathrm{mg} / \mathrm{m}^{2}\right)\end{array}$ & $\begin{array}{l}6 \text { cycles, q21 } \\
\left(70 \mathrm{mg} / \mathrm{m}^{2}\right)\end{array}$ & $\begin{array}{l}6 \text { weeks, q7, } \\
\left(40 \mathrm{mg} / \mathrm{m}^{2}\right)\end{array}$ & $\begin{array}{l}6 \text { months, } 97 \\
\left(36 \mathrm{mg} / \mathrm{m}^{2}\right)\end{array}$ & $\begin{array}{l}6 \text { weeks, q7, } \\
\left(40 \mathrm{mg} / \mathrm{m}^{2}\right)\end{array}$ \\
\hline LHRH Analog & $\begin{array}{l}\text { buserelin } \\
9.45 \mathrm{mg} \\
\text { (1×3 months) }\end{array}$ & $\begin{array}{l}\text { leuprorelin } \\
11.25 \mathrm{mg} \\
\text { (2x3 months) }\end{array}$ & n.d. & $\begin{array}{l}\text { goserelin } \\
10.8 \mathrm{mg} \\
(1 \times 3 \text { months })\end{array}$ & $\begin{array}{l}\text { goserelin } \\
3.6 \mathrm{mg} \\
\text { (3x1 month) }\end{array}$ & $\begin{array}{l}\text { buserelin } 6.6 \mathrm{mg} \\
\text { (3x2 months) }\end{array}$ & $\begin{array}{l}\text { triptorelin } \\
3.75 \mathrm{mg} \\
\text { ( } 4-12 \text { months) }\end{array}$ & n.d. & n.d. & n.d. & n.d. \\
\hline Antiandrogens & $\begin{array}{l}\text { bicaluta-mide } \\
50 \mathrm{mg} / \mathrm{d} \\
\text { ( } 9 \text { weeks) }\end{array}$ & $\begin{array}{l}\text { bicaluta-mide } \\
81 \mathrm{mg} / \mathrm{d} \\
\text { (12 weeks) }\end{array}$ & n.d. & $\begin{array}{l}\text { flutamide } 750 \mathrm{mg} / \mathrm{d} \\
\text { (12 weeks) }\end{array}$ & $\begin{array}{l}\text { bicaluta-mide } \\
50 \mathrm{mg} / \mathrm{d} \\
\text { (12 weeks) }\end{array}$ & $\begin{array}{l}\text { flutamide } 750 \text { mg/d } \\
\text { // bicaluta-mide } \\
50 \text { mg/d (4 weeks) }\end{array}$ & n.d. & n.d. & n.d. & n.d. & n.d. \\
\hline Estramustine & n.d. & $\begin{array}{l}1120 \mathrm{mg} / \mathrm{d} \\
(6 \text { weeks })\end{array}$ & $420 \mathrm{mg} / \mathrm{d}$ for $3 \mathrm{~d}$ & n.d. & $\begin{array}{l}840 \mathrm{mg} / \mathrm{d} \text { for } \\
5 \mathrm{~d}\end{array}$ & n.d. & $\begin{array}{l}600 \mathrm{mg} / \mathrm{m}^{2} \\
(12 \text { weeks) }\end{array}$ & $\begin{array}{l}840 \mathrm{mg} / \mathrm{d} \\
\text { for } 3 \mathrm{~d}\end{array}$ & n.d. & n.d. & n.d. \\
\hline Therapy-weeks & 9 & 6 & 12 & 12 & 12 & 24 & $16-60$ & 18 & 6 & 24 & 6 \\
\hline pCR (\%) & 0 & 11.1 & 0 & 6 & 0 & 3.1 & 5 & 0 & 0 & 0 & 0 \\
\hline pMRD (\%) & 3.33 & n.d. & n.d. & 6 & n.d. & 25 & $31.6^{*}$ & n.d. & n.d. & n.d. & 7.14 \\
\hline \multirow{2}{*}{$\begin{array}{l}\text { iPSA, median, } \\
\text { range (ng/ml) }\end{array}$} & 25.8 & 25.8 & 22.3 & 9.7 & 21.2 & 10.8 & 41 & 16.1 & \multirow[t]{2}{*}{ n.d. } & \multirow[t]{2}{*}{ n.d. } & 12 \\
\hline & $2.1-293$ & $5.1-45.1$ & $0.3-255$ & $0.6-90.8$ & $3.2-71.6$ & $1.6-65.6$ & n.d. & $2.4-175$ & & & $2.5-43.3$ \\
\hline iGl. sc. $\geq 7$ (\%) & 90 & 87.4 & 100 & 95 & n.d. & 91 & 86 & 96 & 93 & 75 & 94 \\
\hline$\geq$ cT3 (\%) & 93.3 & 43.8 & 27 & 28 & 64 & 39 & 86 & 25 & 17.8 & 16 & 27 \\
\hline 2pT3 (\%) & 56.5 & 38.9 & 72.7 & 37 & 36.4 & 44 & 42 & 70 & 82.1 & 62 & 89 \\
\hline SVI (\%) & 53.3 & 11.1 & 45.5 & n.d. & 40.9 & 22 & 37 & 60 & 39.3 & 50 & 32 \\
\hline RO (\%) & 66.7 & 100 & 63.6 & 64.7 & 72.7 & 73 & 74 & 70 & 75 & n.d. & 96 \\
\hline pN1 (\%) & 36.7 & 22.2 & n.d. & 3.9 & 18.1 & 6 & 21 & 10 & 14.3 & 0 & 14 \\
\hline \multirow{2}{*}{$\begin{array}{l}\text { FU, median, } \\
\text { range (months) }\end{array}$} & 48.6 & 18 & 24 & 35 & 23.6 & 42.7 & 53 & 13.1 & 49.5 & 26.5 & 23 \\
\hline & $20-88$ & $1-49$ & n.d. & $23-47$ & $12-55$ & $26-66$ & $30-64$ & $9-18$ & $23-72$ & $4.5-40$ & $1.5-36$ \\
\hline Recur. Pts. (\%) & 55.2 & 22.2 & 55 & 35.1 & 45.4 & 30.0 & 58.0 & 29.0 & 57.0 & 63.2 & 29.0 \\
\hline
\end{tabular}

Abbreviations: CSOS, cancer specific overall survival; cT3, clinical stage T3 with capsular penetration; pT3, pathological stage T3 with capsular penetration; D, docetaxel; FU, follow up; iGl. sC., initial Gleason score; iPSA, initial prostate-specific antigen; LHRH, luteinizing hormone releasing hormone; n.a., not applicable; n.d., not done; pN1, pathological lymph node involvement; pCR, pathological complete response; pMRD, pathological minimal residual disease with $<5 \%$ PC in surgical specimens; *, pMRD with $<10 \%$ PC in surgical specimens; q, treatment interval of 7 or 21 days; R0, negative surgical resection margin; RP, radical prostatectomy; Recur. Pts., patients with recurrent PC; RP/Rad, 12 patients treated with RP and 10 with external beam radiation; SVl, seminal vesicle invasion. 


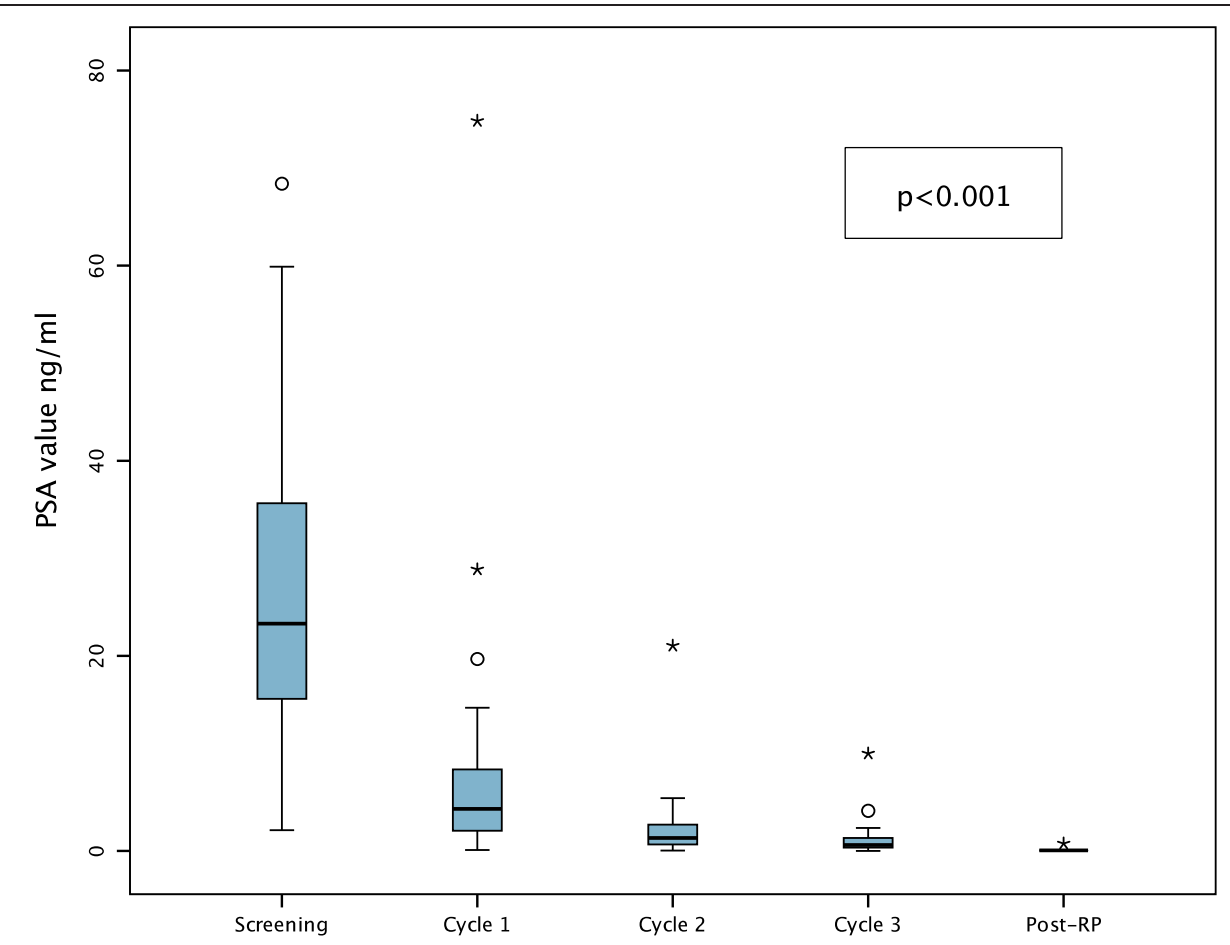

Figure 1 Boxplot diagram showing prostate specific antigen (PSA)-response by treatment interval in the complete cohort of patients; extreme values $(n=3)$ at screening are not presented for graphing reasons; Abbreviations: ${ }^{\circ}$, outliers; *, extreme outliers; RP, radical prostatectomy.

leucopenia in $54 \%$ and neutropenia in $90 \%$, when analyzed one week after D administration. Thus hematotoxicity was increased compared to weekly D monotherapy (0-14\%) and D + CAB (0-15\%) $[12,13,15,16]$. Our increased hematotoxicity might be caused by the 3-weekly full dose docetaxel regimen and especially by blood collection at the nadir of leucopenia.

Surgical variables are in accordance with literature. Resectability was partly hindered due to callosity as reported earlier for neoadjuvant docetaxel or CAB [7,12,13,15-19]. The rate of positive surgical margins in our series reflects the midrange of earlier published trials (Table 4). With respect to functional outcome, $97 \%$ of our patients are continent, similar to other trials reporting $89-95 \%$ continence rates $[7,12,13]$. Erectile function assessments revealed sexual activity in $46 \%$ of our patients, whereas $15.4 \%$ returned to baseline potency. Regrettably the majority did not try erection aids. Overall, despite explicit locally advanced stages our patients experienced excellent continence and sexual activity after RP. Comparing the excellent continence rates across neoadjuvant studies, to the results from the CaPSURE study with $63 \%$ continence and $20 \%$ potency after sole RP, the magnitude of presurgical treatment might be the amelioration of the functional outcome in patients with locally advanced stages treated with RP [20].

Several trials used a pCR rate of $10-40 \%$ as primary endpoint, but failed [7,13,15-17]. Using combinations of weekly D + CAB a pCR rate of 3-6\% and pMRD rates of
$6-25 \%$ were demonstrated $[15,16]$. In our study only one patient presented a pMRD (3\%) and none a pCR. This was surprising as we used the potentially more active 3 weekly docetaxel regime. The superior results by Chi et al. might be a consequence of prolonged treatment of 24 weeks [16]. Overall neoadjuvant regimens with $\mathrm{D} \pm$ $\mathrm{CAB}$ seem unable to achieve relevant $\mathrm{pCR}$ or $\mathrm{pMRD}$ rates [17]. A marginal improvement was observed by adding estramustine phosphate (EMP) to D+ADT (Table 4).

With respect to downstaging we observed a partial PSA response in $100 \%$ and a complete PSA response in $13 \%$. The PSA-value reduction was $97 \%$, similar to weekly D + CAB or D + EMP, but superior to docetaxel monotherapy with 64\% PSA-decline and 24\% partial response [12,13,15,16,21]. In addition we observed local clinical downstaging with tumor volume reduction in $96 \%$ and T-stage shift in $32 \%$. The overall tumor volume decrease was $46 \%$, thus being superior to D monotherapy with $26 \%$, whereas our $\mathrm{T}$-stage reduction rate is similar to ADT alone with $30 \%[13,22]$. Finally we observed pathological downstaging in $48 \%$, which was superior to ADT alone (15\%) and comparable to D + $\mathrm{ADT}+\mathrm{EMP}$ achieving 42\% [7,22]. In summary, our results attained the primary endpoint with a downstaging proportion of $>40 \%$ for PSA decrement, tumor volume decrease and pathological downstaging but not for clinical T-stage shift. 

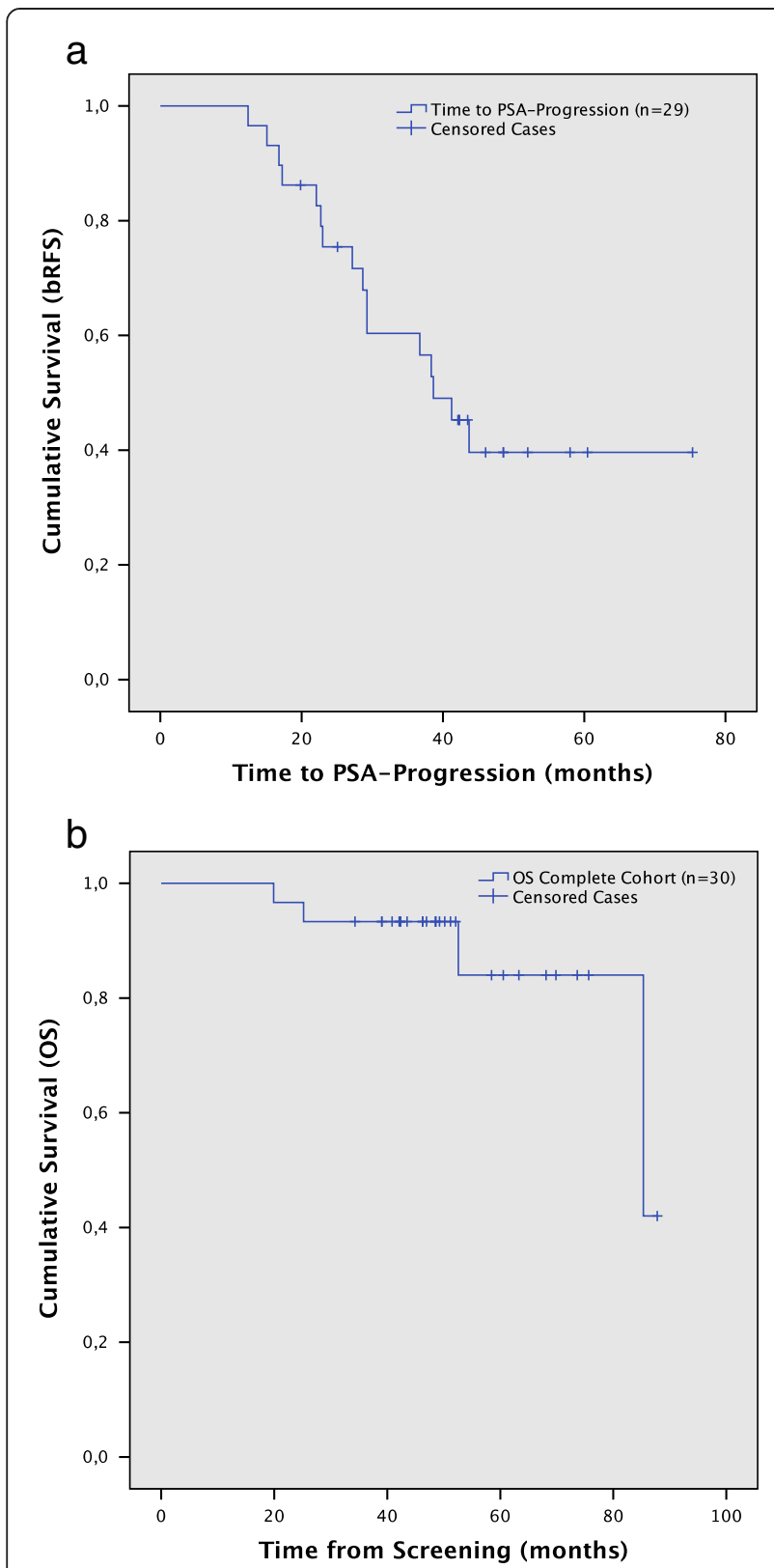

Figure 2 Kaplan-Meier plot for a. biochemical recurrence free survival (bRFS), in patients defined as therapy responders $(n=29)$. b. overall survival (OS) in the complete cohort of patients.

Neoadjuvant trials with long-term FU and relevant recurrence rates are rare. Using D + ADT + EMP a recurrence rate of $58 \%$ was observed after a FU of 53 months [7]. Similarly D monotherapy revealed a recurrence rate of $57 \%$ after a median FU of 50 months, equal to a matched control group [14]. In our trial the biochemical recurrence rate was 55\% after a FU of 49 months. Thus our results are similar to the cited studies, although comparability is hindered due to different inclusion criteria. The 5-year bRFS in our cohort was increased to $40 \%$, when compared to the predicted median of $10 \%$ [1]. However, the interpretation of our results is limited due to individualized adjuvant strategies. Further, interesting results were presented following weekly $\mathrm{D}+\mathrm{CAB}$ with a recurrence rate of only $30 \%$ after a moderate briefer FU of 43 months [16]. The difference with our results might be a consequence of the longer treatment interval as well as patient selection with lower PSA-values, fewer ECE and lymph node involvement (Table 4).

Although our trial gives additional clinical information and confirms significant clinical activity of neoadjuvant D + $\mathrm{CAB}$, our study has certain limitations especially with respect to bRFS. Adjuvant treatment was not uniformly defined. This is in accordance with literature, but contrasts with other trials that excluded adjuvant therapy until progression $[7,12,13,15,16,23]$. However due to underpowered trials, limited FU-times, variations on post-surgical management, lack of randomization and comparability, the ideal neoadjuvant approach is not yet defined [15,17]. Maybe the randomized phase III trial CALGB 90203 comparing neoadjuvant $\mathrm{D}+\mathrm{ADT}$ vs. RP alone, with the primary endpoint of 3 -year biochemical progression-free survival, is capable to answer the remaining questions. But to the best of our knowledge results are not on short call [24].

\section{Conclusions}

To our knowledge we are the first to present a long time FU of a phase II trial, investigating a short-term neoadjuvant therapy with 3-weekly full dose docetaxel, combined with $\mathrm{CAB}$ in locally advanced and high-risk PC patients scheduled for RP. The regimen is feasible, despite a high rate of severe neutropenia and leucopenia. Significant clinical activity was observed, despite absence of pCR. Surgical variables revealed an excellent functional outcome. Finally a precariously $30 \%$ improvement of the 5 -year bRFS was achieved.

\section{Methods}

This single-center non-randomised phase II trial was conducted at the Department of Urology, Klinikum rechts der Isar, Technische Universität München. The study was approved by the institutional review board and the regulatory authorities and was performed in accordance with the ethical standards of the Declaration of Helsinki. All subjects gave written informed consent. Main eligibility criteria were adenocarcinoma of the prostate, absence of metastatic disease and a biochemical recurrence risk of $>40 \%$ within 5 years, according to Kattan's preoperative nomogram [1].

Primary objectives were downstaging effects, reflected by PSA-value decrement and local tumor reduction by clinical and pathological criteria. Secondary objectives were the $\mathrm{pCR}$ and pathological minimal residual disease (pMRD) rate, the toxicity profile and operability, along with time to PSA progression, 5-year biochemical recurrence free survival (bRFS) and overall survival (OS). 


\section{Treatment}

Presurgical treatment consisted of $\mathrm{CAB}$ comprising bicalutamide $50 \mathrm{mg} /$ day p.o. starting day 1 until the day before RP with trimestral buserelin $9.45 \mathrm{mg}$ s.c. on day 3 and three cycles of docetaxel chemotherapy $\left(75 \mathrm{mg} / \mathrm{m}^{2}\right)$ on days 8,29 and 50 in combination with prednisolone $10 \mathrm{mg} /$ day p.o. starting on day 9. Dexamethasone (8 mg p.o.) was administered 12 hours before and after docetaxel as well as $60 \mathrm{~min}$ before. A dose reduction of docetaxel to $60 \mathrm{mg} / \mathrm{m}^{2}$ and a treatment deferral of 21 days were allowed. All patients underwent open retropubic RP including extended bilateral pelvic lymph node dissection up to the aorta. Adjuvant radiation and hormonal therapies were individualized according to pathological results $[13,23]$. NCHT was aborted in case of unacceptable toxicities, progression or on patients' request.

\section{Staging and clinical activity}

Tumor staging included digital rectal examination, abdominal and transrectal ultrasound, chest X-ray, bone- and computed tomography scans $(\mathrm{CT})$ or magnetic resonance imaging (MRI) of the pelvis. Pelvic lymph nodes were considered non-metastatic if the maximum diameter did not exceed $1.5 \mathrm{~cm}$. Local clinical downstaging was assessed by MRI of the prostate with endorectal coil (1.5 T, Magnetom Avanto, Siemens, Germany) before and after NCHT. T2weighted sequences in three planes, axial T1-weighted and a dynamic-contrast-enhanced sequence were analyzed independently by a board certified radiologist. Median prostate and tumor volumes were calculated [13,25-27]. Tumor volume was determined by measuring the maximum tumor area in the axial plane and the longest cranio-caudal diameter. In case of multiple tumor nodules, each was measured separately. Pathologic specimens were classified according to the "Union international contre le cancer" version 2002. Gleason grading is not valid following NCHT, consequently it was not determined $[7,15]$. The absence of $\mathrm{PC}$ in the histo-pathological sections was defined as $\mathrm{PCR}$ and tumor volumes $<5 \%$ as pMRD [15]. In addition, pathologic downstaging, comparing initial stages on MRI with histopathological stages, was analyzed [7,13,22]. PSA response was assessed before RP and latest 3 months post-RP. Before RP, a PSA reduction of $>50 \%$ indicated partial response and PSA-levels $<0.2 \mathrm{ng} / \mathrm{ml}$ a complete response [15]. After RP, patients with PSA-values $<0.07 \mathrm{ng} / \mathrm{ml}$ were deemed therapy responders. Biochemical recurrence was defined by two PSA increases $>0.2 \mathrm{ng} / \mathrm{ml}$ [28].

Surgical variables were recorded implying the functional outcome. Continence was defined as the use of no pads and erectile function using the erection hardness score (E0-E4) [7,29]. Adverse events (AE) were registered according to Common Terminology Criteria (CTCAE 3.0), including dose reductions and treatment deferrals. Additional hematologic analyses were performed one week after docetaxel application.

\section{Statistical analysis}

This trial was conducted as an intent to treat approach [30]. Sample sizes were calculated using the software NQuery version 7.0. With a sample size of 24 patients, a one-sided $97.5 \%$ confidence interval for the downstaging proportion, using the large sample normal approximation, will extend $20 \%$ from the observed proportion for an expected proportion of $40 \%$. Analyses were performed using SPSS version 20 (SPSS Inc., Chicago, IL, USA). Changes in continuous measures over time were determined using the Wilcoxon signed-rank test and linear trend analyses using the Kruskal-Wallis test. Applying a Bonferroni correction, a p-value of $<0.025$ was considered statistically significant. Estimates of survival were analyzed using the Kaplan-Meier method. OS was defined as the elapsed time from screening to death and time to PSA progression as time from the first study treatment to biochemical progression [30].

\section{Competing interest}

The authors have no actual or potential conflict of interest in relation to this article to declare. The study was supported by Sanofi-Aventis, Frankfurt, Germany.

\section{Authors' contributions}

MT and HRK analyzed data and wrote the manuscript, UT contributed to concept design, JG and MR directed the study and contributed to data interpretation, $\mathrm{MT}, \mathrm{TH}, \mathrm{MMH}, \mathrm{TM}$ and $\mathrm{MA}$ performed the research and contributed to data collection, BJK and ME evaluated imaging datasets, $\mathrm{KH}$ edited the manuscript. All authors read and approved the final manuscript.

\section{Acknowledgements}

We thank Janet Mindes, PhD, NYC, USA, for her editing assistance as a native English speaker, the Institute for Medical Statistics, Technische Universität München, Germany for counseling, and Bettina Reimer, earning her doctorate on this work.

\section{Author details}

${ }^{1}$ Department of Urology, Klinikum rechts der Isar, Technische Universität München, Ismaninger Str. 22, Munich 81675, Germany. ${ }^{2}$ Department of Radiology Klinikum rechts der Isar, Technische Universität München, Ismaninger Str. 22, Munich 81675, Germany. ${ }^{3}$ Department of Nuclear Medicine, Universitätsklinikum Rostock, Schillingallee 35, Rostock 18057, Germany.

Received: 27 December 2013 Accepted: 25 February 2014 Published: 5 March 2014

\section{References}

1. Kattan MW, Eastham JA, Stapleton AMF, Wheeler TM, Scardino PT: A preoperative nomogram for disease recurrence following radical prostatectomy for prostate cancer. J Natl Cancer Inst 1998, 90:766-771.

2. D'Amico AV, Whittington R, Malkowicz SB, Schultz D, Blank K, Broderick GA, Tomaszewski JE, Renshaw AA, Kaplan I, Beard CJ, Wein A: Biochemical outcome after radical prostatectomy, external beam radiation therapy, or interstitial radiation therapy for clinically localized prostate cancer. JAMA 1998, 280(11):969-974.

3. Sonpavde G, Sternberg CN: Neoadjuvant systemic therapy for urological malignancies. BJU Int 2010, 106(1):6-22.

4. Bolla M, Collette L, Blank L, Warde P, Dubois JB, Mirimanoff RO, Storme G, Bernier J, Kuten A, Sternberg C, Mattelaer J, Lopez Torecilla J, Pfeffer JR, Lino Cutajar C, Zurlo A, Pierart M: Long-term results with immediate androgen suppression and external irradiation in patients with locally advanced prostate cancer (an EORTC study): a phase III randomised trial. Lancet 2002, 360(9327):103-106. 
5. Warde $P$, Mason M, Ding K, Kirkbride $P$, Brundage M, Cowan R, Gospodarowicz M, Sanders K, Kostashuk E, Swanson G, Barber J, Hiltz A, Parmar MK, Sathya J, Anderson J, Hayter C, Hetherington J, Sydes MR, Parulekar W, NCIC CTG, PR.3/MRC UK PRO7 investigators: Combined androgen deprivation therapy and radiation therapy for locally advanced prostate cancer: a randomised, phase 3 trial. Lancet 2011, 378(9809):2104-2111.

6. Shelley MD, Kumar S, Wilt T, Staffurth J, Coles B, Mason MD: A systematic review and meta-analysis of randomised trials of neo-adjuvant hormone therapy for localised and locally advanced prostate carcinoma. Cancer Treat Rev 2009, 35(1):9-17.

7. Prayer-Galetti T, Sacco E, Pagano F, Gardiman M, Cisternino A, Betto G, Sperandio P: Long-term follow-up of a neoadjuvant chemohormonal taxane-based phase II trial before radical prostatectomy in patients with non-metastatic high-risk prostate cancer. BJU Int 2007, 100(2):274-280.

8. Petrylak DP, Tangen CM, Hussain MH, Lara PN Jr, Jones JA, Taplin ME, Burch PA, Berry D, Moinpour C, Kohli M, Benson MC, Small EJ, Raghavan D, Crawford ED: Docetaxel and estramustine compared with mitoxantrone and prednisone for advanced refractory prostate cancer. N Engl J Med 2004, 351(15):1513-1520.

9. Berthold DR, Pond GR, Soban F, de Wit R, Eisenberger M, Tannock IF: Docetaxel plus prednisone or mitoxantrone plus prednisone for advanced prostate cancer: updated survival in the TAX 327 study. J Clin Oncol 2008, 26(2):242-245.

10. Sartor AO: Progression of metastatic castrate-resistant prostate cancer: impact of therapeutic intervention in the post-docetaxel space. $J$ Hematol Oncol 2011, 4:18

11. Huang $X$, Chau CH, Figg WD: Challenges to improved therapeutics for metastatic castrate resistant prostate cancer: from recent successes and failures. J Hematol Oncol 2012, 5:35

12. Dreicer R, Magi-Galluzzi C, Zhou M, Rothaermel J, Reuther A, Ulchaker J, Zippe C, Fergany A, Klein EA: Phase II trial of neoadjuvant docetaxel before radical prostatectomy for locally advanced prostate cancer. Urology 2004, 63(6):1138-1142.

13. Febbo PG, Richie JP, George DJ, Loda M, Manola J, Shankar S, Barnes AS, Tempany C, Catalona W, Kantoff PW, Oh WK: Neoadjuvant docetaxel before radical prostatectomy in patients with high-risk localized prostate cancer. Clin Cancer Res 2005, 11(14):5233-5240.

14. Magi-Galluzzi C, Zhou M, Reuther AM, Dreicer R, Klein EA: Neoadjuvant docetaxel treatment for locally advanced prostate cancer: a clinicopathologic study. Cancer 2007, 110(6):1248-1254.

15. Mellado B, Font A, Alcaraz A, Aparicio LA, Veiga FJ, Areal J, Gallardo E, Hannaoui N, Lorenzo JR, Sousa A, Fernandez PL, Gascon P: Phase II trial of short-term neoadjuvant docetaxel and complete androgen blockade in high-risk prostate cancer. Br J Cancer 2009, 101(8):1248-1252.

16. Chi KN, Chin JL, Winquist E, Klotz L, Saad F, Gleave ME: Multicenter phase II study of combined neoadjuvant docetaxel and hormone therapy before radical prostatectomy for patients with high risk localized prostate cancer. J Urol 2008, 180(2):565-570.

17. Sella A, Zisman A, Kovel S, Yarom N, Leibovici D, Lindner A: Neoadjuvant chemohormonal therapy in poor-prognosis localized prostate cancer. Urology 2008, 71(2):323-327.

18. Narita S, Tsuchiya N, Kumazawa T, Maita S, Numakura K, Obara T, Tsuruta H, Saito M, Inoue T, Horikawa Y, Satoh S, Nanjyo H, Habuchi T: Short-term clinicopathological outcome of neoadjuvant chemohormonal therapy comprising complete androgen blockade, followed by treatment with docetaxel and estramustine phosphate before radical prostatectomy in Japanese patients with high-risk localized prostate cancer. World J Surg Oncol 2012, 10:1.

19. van der Kwast TH, Têtu B, Candas B, Gomez JL, Cusan L, Labrie F: Prolonged neoadjuvant combined androgen blockade leads to a further reduction of prostatic tumor volume: three versus six months of endocrine therapy. Urology 1999, 53(3):523-529.

20. Hu JC, Elkin EP, Pasta DJ, Lubeck DP, Kattan MW, Carroll PR, Litwin MS: Predicting quality of life after radical prostatectomy: results from CaPSURE. J Urol 2004, 171(2 Pt 1):703-708.

21. Kim WY, Whang YE, Pruthi RS, Baggstrom MQ, Rathmell WK, Rosenman JG, Wallen EM, Goyal LK, Grigson G, Watkins C, Godley PA: Neoadjuvant docetaxel/estramustine prior to radical prostatectomy or external beam radiotherapy in high risk localized prostate cancer: a phase II trial. Urol Oncol 2011, 29(6):608-613.
22. Schulman CC, Debruyne FM, Forster G, Selvaggi FP, Zlotta AR, Witjes WP: 4-year follow-up results of a European prospective randomized study on neoadjuvant hormonal therapy prior to radical prostatectomy in T2-3N0M0 prostate cancer. European Study Group on Neoadjuvant Treatment of Prostate Cancer. Eur Urol 2000, 38(6):706-713.

23. Hussain M, Smith DC, El-Rayes BF, Du W, Vaishampayan U, Fontana J, Sakr W, Wood D: Neoadjuvant docetaxel and estramustine chemotherapy in high-risk/locallyadvanced prostate cancer. Urology 2003, 61(4):774-780.

24. Eastham JA, Kelly WK, Grossfeld GD, Small EJ: Cancer and Leukemia Group B (CALGB) 90203: a randomized phase 3 study of radical prostatectomy alone versus estramustine and docetaxel before radical prostatectomy for patients with high-risk localized disease. Urology 2003, 62(Suppl 1):55-62.

25. D'Amico AV, Chang E, Garnick M, Kantoff $P$, Jiroutek M, Tempany CM: Assessment of prostate cancer volume using endorectal coil magnetic resonance imaging: a new predictor of tumor response to neoadjuvant androgen suppression therapy. Urology 1998, 51(2):287-292.

26. D'Amico AV, Halabi S, Tempany C, Titelbaum D, Philips GK, Loffredo M, McMahon E, Sanford B, Vogelzang NJ, Small EJ, Cancer and Leukemia Group B: Tumor volume changes on 1.5 tesla endorectal MRI during neoadjuvant androgen suppression therapy for higher-risk prostate cancer and recurrence in men treated using radiation therapy results of the phase II CALGB 9682 study. Int J Radiat Oncol Biol Phys 2008, 71(1):9-15.

27. Vuky J, Porter C, Isacson C, Vaughan M, Kozlowski P, Picozzi V, Corman J: Phase II trial of neoadjuvant docetaxel and gefitinib followed by radical prostatectomy in patients with high-risk, locally advanced prostate cancer. Cancer 2009, 115(4):784-791.

28. Mottet N, Bellmunt J, Bolla M, Joniau S, Mason M, Matveev V, Schmid HP Van der Kwast T, Wiegel T, Zattoni F, Heidenreich A: EAU guidelines on prostate cancer. Part II: Treatment of advanced, relapsing, and castration-resistant prostate cancer. Eur Urol 2011, 59(4):572-583.

29. Goldstein I, Lue TF, Padma-Nathan H, Rosen RC, Steers WD, Wicker PA: Sildenafil Study Group. Oral sildenafil in the treatment of erectile dysfunction. 1998. J Urol 2002, 167(2 Pt 2):1197-1203.

30. Bubley GJ, Carducci M, Dahut W, Dawson N, Daliani D, Eisenberger M, Figg WD, Freidlin B, Halabi S, Hudes G, Hussain M, Kaplan R, Myers C, Oh W, Petrylak DP, Reed E, Roth B, Sartor O, Scher H, Simons J, Sinibaldi V, Small EJ, Smith MR, Trump DL, Robin V, Wilding G: Eligibility and response guidelines for phase II clinical trials in androgen-independent prostate cancer: recommendations from the Prostate-Specific Antigen Working Group. J Clin Oncol 1999, 17(11):3461-3467.

doi:10.1186/1756-8722-7-20

Cite this article as: Thalgott et al.: Long-term results of a phase II study with neoadjuvant docetaxel chemotherapy and complete androgen blockade in locally advanced and high-risk prostate cancer. Journal of Hematology \& Oncology 2014 7:20

\section{Submit your next manuscript to BioMed Central and take full advantage of:}

- Convenient online submission

- Thorough peer review

- No space constraints or color figure charges

- Immediate publication on acceptance

- Inclusion in PubMed, CAS, Scopus and Google Scholar

- Research which is freely available for redistribution 